\title{
Pragmatic competence and social power awareness: The case of written and spoken discourse in non-native English environments
}

\author{
CARMen PÉREZ-Sabater \& Begoña Montero-FletA* \\ Universitat Politècnica de València
}

Received: 26/01/2014. Accepted: 18/07/14.

\begin{abstract}
Following one of the new challenges suggested by the Common European Framework of Reference for Languages, a treatment was developed to enhance pragmatic competence, since this competence is not easy to acquire by non-native speakers. Within this context, we focused on pragmatic awareness in the workplace, an area of expertise in growing demand today. Specifically, we centred on the power variable and the distinction between powerful and powerless speech styles through negotiation, co-planning and goal-oriented interactions. Powerful speech has been envisaged as the language of success; however, the positive implications of powerless speech in the workplace have been recently posited. After an instruction phase, the results confirmed that powerless markers were prone to be used adequately in writing, while in oral interactions non-native speakers were not able to employ them fluently or, at least, naturally. The treatment encouraged the critical engagement of students in the process of learning new ways of communicating at work.
\end{abstract}

KEYWORDS: Pragmatic competence, powerful vs. powerless style, discourse markers, Common European Framework of Reference for Languages (CEFR), workplace interactions.

\section{RESUMEN}

En relación a uno de los retos planteados por el Marco Común Europeo de Referencia para las Lenguas (MCERL), presentamos un estudio para desarrollar la competencia pragmática. Centrándonos en la conciencia pragmática en entornos laborales, el estudio dedica atención especial a la variable de poder y a la distinción entre estilos de lenguaje con o sin poder por medio de actividades de negociación, co-planificación e interacción orientada a objetivos. El lenguaje de poder se ha considerado siempre una garantía de éxito. Sin embargo, se han señalado recientemente implicaciones positivas del lenguaje sin poder en entornos laborales. Tras una fase de instrucción los resultados confirmaron el uso adecuado de marcadores de ausencia de poder en el lenguaje escrito; por el contrario, en las interacciones orales se observó una mayor dificultad en el uso fluido o natural de dichos marcadores discursivos. La actividad propició la participación crítica en el proceso de aprendizaje de formas de comunicación en ámbitos laborales.

PALABRAS CLAVE: Competencia pragmática, atenuación lingüística, marcadores discursivos, Marco Común Europeo de Referencia para las Lenguas (MCERL), interacciones laborales.

*Address for correspondence: Carmen Pérez-Sabater. Departamento de Lingüística Aplicada, Universitat Politècnica de València, Spain. E-mail: cperezs@idm.upv.es 


\section{INTRODUCTION}

In the last two decades, studies on language learning have highlighted that we need more than the knowledge of words and grammar in order to communicate successfully in a language; we need to acquire pragmatic competence, i.e., the ability to communicate and interpret a message as it is intended to achieve its communicative aim (Fraser, 2010). More specifically, second language acquisition research has emphasized the importance of developing pragmatic competence in a language; for example, Kasper and Blum-Kulka (1993), Koike and Pearson (2005) and Wishnoff (2000), among others, have dealt with the acquisition of pragmatic fluency in L2 and its effective instruction.

On the other hand, in the current working environments in Western societies, the incorporation of new technologies and the integration of multicultural workers are changing the face of work. In this concern, Newton and Kusmiersczyk (2011: 74) point out that "the nature and role of workplace language and the literacy demands of work are changing in the face of increasingly multicultural workplaces and global communication networks". Accordingly, recent research on language teaching for the labour market has focused on successful participation in the new workplace. Apart from core and advanced fundamental knowledge of their field, higher education students must acquire competences and attitudes that require new frameworks for learning that may enable the development of professional skills such as cooperation within and among employees and management teams, mutual understanding, negotiation, and co-planning (Duff, 2005; Halvorsen, 2013; Yates \& Springall, 2010).

However, despite the growing body of research devoted to these areas, few studies have been undertaken to evaluate pragmatic competence and social power awareness in the workplace, and the role of classroom-based support to develop this area of language proficiency, as Marra, Holmes and Riddiford (2009), Riddiford (2007), or Riddiford and Joe (2010) suggest. Thus, the innovative side of the empirical study reported in this paper is to look beyond the linguistic outcomes in the English language syllabus and pursue the development of pragmatic competence in L2. The research aims at filling the gap in the development of pragmatic competence, by centring on the distinction between powerful and powerless language. Particularly, our study addresses pragmatic acquisition for the workplace in a specialized learning context with a focus on the comparison of written and spoken discourse within the recommendations of the Framework, an innovative field of research in second language learning. This article complements previous research by the authors on the adaptation of the new university curricula to the recommendations of the Common European Framework of Reference for Languages (CEFR) (see, e.g., Pérez-Sabater, 2012).

Following the indication of the CEFR and the labour market requirements, this article describes a treatment which aimed at these general objectives: 
1. To raise students' critical language awareness, focusing on work related domains.

2. To enhance the pragmatic competence of our students; to distinguish between powerful and powerless speech styles, centring on the correct use of powerless language.

3. To comparatively analyse written vs. oral students' discourse from the point of view of the powerless discourse markers used.

Along with these objectives, the study here addressed aimed at testing the following hypotheses:

Hypothesis 1: After an instruction phase on powerful and powerless speech styles, students will show a better command of pragmatic competence in both written and spoken contexts.

Hypothesis 2: Non-native written discourse is more prone to contain powerless markers than spoken discourse.

The organization of the paper has this format: once the topic under study and the objectives have been introduced in this section, Section 2 describes the theoretical framework of the article starting by the identification of powerful and powerless speech styles in pragmatics followed by an outline of the new recommendations put forward by the CEFR about the inclusion of pragmatic competence in the new learning syllabi, which will anticipate the methodological approach undertaken. Section 3 describes the treatment devised and presents the methodology used. Section 4 shows the pre-treatment and post-treatment data comparatively and the interpretation of the results obtained according to the variables analysed. Section 5 discusses the results and sheds light on the conclusions reached. Finally, section 6 envisages further lines of research on the topic.

\section{THEORETICAL FRAMEWORK}

\subsection{Powerful and powerless style}

Pragmatics can be subdivided into two components, pragmalinguistics and sociopragmatics (Leech, 1983). The former refers to the resources for conveying communicative acts and relational or interpersonal meanings. On the other hand, sociopragmatics, in other words, the social dimension of pragmatics, studies the values of social power, social distance, degree of imposition and their role in the election of politeness strategies in different cultures. As Blum-Kulka (1997: 53) suggests, social variables may affect "not only the choice of politeness strategies, but also the sequential structure of the discourse". One social variable 
that has received a great deal of attention is power. Specifically, much research has been dedicated to language situations of social power, such as the courtroom where the language style may vary according to the social power of speakers (e.g., O'Barr, 1982). The correspondence between gender differences and social power has also been studied profoundly by scholars; see, for example, Grob, Meyers and Shuh (1997) or Michael, Chrone, Muthusamy and Veeravagu (2010) for variation observed in men's and women's speech styles.

Another point that has drawn the attention of academics has been the study of social power in work domains and business contexts. Among the many studies carried out during the last thirty years, the influential article by Bradac and Mulac (1984) explores power of style in a hypothetical employment interview. Their analysis of hedges, tags, intensifiers, polite forms and hesitations concludes that it is reasonable to distinguish between powerless and powerful linguistic forms. Regarding power and gender, in Bradac and Mulac (1984) the connection between power of style and gender seems to be weak, unlike the conclusions yielded by studies on gender and powerless style such as Lakoff's (1972). Recent studies on powerful versus powerless styles and work situations have emphasized the effects of speech style and job promotions (Fragale, 2006) or impression management techniques in negotiating candidates' expertise for a job (Lipokvsky, 2010).

In general, powerless style consists in the use of what Fraser (1980) calls mitigating devices such as indirectness, distancing techniques or disclaimers, among others. Scholars have identified some linguistic markers characterizing powerless style. The relative absence of these markers will indicate a powerful style, which exhibits a small number of these markers and is more direct, categorical and assertive. In concordance with Bradac and Mulac (1984), Fragale (2006), Fraser (1980) and Ng and Bradac (1993) the linguistic markers used to characterize powerless styles could be the following:

1. Hedges or validity qualifiers (sort of, kind of, pretty much), words that "make things fuzzier or less fuzzy" (Lakoff, 1972: 195).

2. Tag questions (isn't it?), a usual resource to bring the hearer into the discussion (Coates, 1988), and ask for his/her opinion.

3. Intensifiers or boosters (he really did, very), markers which express conviction consistently and represent a strong claim about a state of affairs (Hyland, 1998b). In the workplace, they transmit a general positive tone (Yeung, 2007).

4. Formal addresses and polite forms (yes, sir; thank you very much), strategies which imply the use of good manners or etiquette.

5. Hesitations (well, ah, uh, aww, uhhh, I, um, don't know), although apparently may indicate some linguistic incompetence, they usually make speakers sound more native like (Lin et al., 2012). 
6. Word repetition, a resource triggered by speakers as a filler or repair echoing the immediate repetition of the previous speaker's most current utterance (Tannen, 1987). This technique is particularly useful for interactive purposes in conversation (Gómez González, 2012; Tanskanen, 2006).

7. Distancing techniques (e.g. passive instead of active, I was given the opportunity to carry out that task) suppress the direct involvement of an agent in an action (Chafe, 1982).

8. Disclaimers (if I'm not wrong, I hate to do this, I am not an expert, but ...) are used to limit the certainty of a statement.

9. Parenthetical verbs (I guess/suppose/reckon), linguistic markers that indicate the speaker's commitment to the proposition expressed.

10. Personalized epistemic modals (it seems to me, it looks like, it looks as if) are used as a rhetorical technique to convey personal evaluation and to render the utterance less threatening.

More recently, Fraser (2010) includes some of these categories in what he calls "English hedges". Functions such as politeness, indetermination, indirectness, vagueness, and modality are closely related to hedging (Taweel et al., 2011). Hence, the various names scholars have given to this rhetorical mitigating strategy: adaptors, attenuators, deintensifiers, diminishers, down-toners or minimizers (Fraser, 2010). For the purpose of this study, we distinguish among the 10 linguistic markers described above. The cover term powerless markers will be used throughout this research, as there is not a clear-cut list of hedges and the generic hedging term for these markers has not been unanimously adopted by scholars.

Studies have related hedging to a decrease in the strength of the claims that are made in an argument and undermine persuasive attempts (Blankenship \& Holtgraves, 2005). There is a general concern on the negative value of these rhetorical devices regarding the listener's persuasion on the information provided by the speaker; in fact, hedges modify the meaning of a statement by commenting on the uncertainty of the information stated. As a result, hedging devices seem to diminish the claims made in the argument and contribute to lead to less persuasion and weaker evaluations.

In the last few years, however, research has shown positive implications regarding the incorporation of hedging and powerless markers in discourse. Durik et al.'s (2008) research on academic writing found that hedges describing data statements and/or hedges that use colloquial language can, but do not always, undermine persuasive attempts. The research undertaken by these authors support the use of hedges in academic writing and point out their relevant role in the statement of experimental results, a fact which made Durik, Britt, Reynolds and Storey (2008) conclude that in some contexts hedging can be viewed as professional and do not necessarily lead to negative perceptions. 
Likewise, in work domains, some commonly accepted assumptions of the rewarding benefits of powerful language have been recently nuanced by scholars. Traditionally, it has been broadly documented that there is a consistent relationship between speech styles and subsequent status attainment, in other words, that one's speech style affects one's ability to get promoted or be respected. Thus, powerful styles represent always the 'language of success', while, correspondingly, unassertive styles are the 'language of failure'; for example, Parton et al. (2002) demonstrate that in the employment interview a powerful speech style favours positive attributions of competence and employability. Notwithstanding this, voices against this unanimously assumed and oversimplistic premise claim that powerless language can also be rewarding depending on the organizational context. In her analysis of the effects of speech style on status conferral when working collaboratively in groups, Fragale has adeptly noted that individuals using powerless speech may benefit when attributions of communality are weighted "multiple languages may lead to status attainment, depending on the particular features of the task or organizational context in question" (Fragale, 2006: 259).

A final remark should concern the role of powerful and powerless pragmatic markers in cross-cultural pragmatics. Cultures vary greatly in their interactional styles. Studies on cultural variation have underlined that in Mediterranean cultures, request acts are more direct, although not necessarily impolite (Blum-Kulka, 1997). This may have a clear effect on nonnatives' speech acts, especially in requests, which may be straightforward, assertive, categorical and with a substantial lack of powerless style, a kind of speech that may sound impolite to native speakers of English. Thus, a good command of these pragmatic markers may be crucial to the language learner. To this end, The Common European Framework of Reference for Languages (CEFR) has incorporated its study into the European language curricula.

\subsection{Pragmatic competence and the CEFR}

The Framework supports that the new syllabi in language learning should promote not only the practice of language skills but also the learning of sociocultural knowledge and the development of pragmatic competence. As a result, besides linguistic knowledge, special attention must be dedicated in the language class to some aspects of a particular European society and its culture, and to enhance pragmatic acquisition. The new directives for language learning in Europe, which seek to make it easier for teachers and learners to communicate across languages and educational sectors (North, 2004), have significantly increased the role of pragmatic competence in language learning.

According to the CEFR, pragmatic competence should be enhanced by awareness raising, since this may be the only possible method of teaching in this area of language use (Markkanen \& Schröder, 1997). In this concern, the activities developed in the treatment carried out try to follow the suggestions of the CEFR on the context of language use, that is, 
the situation where the language is employed. In this study, we focus on the particular context or domain of our students' career. We prepare them to operate in the occupational domain of engineering; specifically, in the particular situations our students "will need/be equipped/be required to handle" (CEFR, 2001: 46) in the institutions, organisations and actions with which they will be concerned.

The Framework suggests that, among the communicative tasks recommended for workplace interactions, students should be able to "communicate appropriately with superiors, colleagues and subordinates" (2001: 54). From the types of tasks recommended to this end, in this research we used simulations and role-plays. The CEFR also proposes strategies to maximize effectiveness in language learning. Among the examples of activities and strategies in oral production prescribed, we centred on "acting out a rehearsed role". Moreover, regarding classes of cognitive and collaborative strategies dealing with managing co-operation and interaction, the Framework recommends the use of negotiation, coplanning, and practical goal-oriented co-operation, where the "language user acts alternately as speaker and listener with one or more interlocutors" (2001: 73). Particularly, for level B2, upper-intermediate, the CEFR indicates that students should be able to interact with a degree of fluency and spontaneity that makes regular interaction with native speakers quite possible, adjusting "to the changes of direction, style and emphasis normally found in conversation" (CEFR, 2001: 35).

Current commercial textbooks (e.g. Pledger, 2007) include the practice of the collaborative strategies recommended by the CEFR such as turntaking and turngiving, framing the issue and establishing a line of approach, proposing and evaluating solutions, recapping and summarizing the point reached, and mediating in a conflict. A big number of Internet sites also provide answers to typical negotiating and co-planning techniques from several perspectives. These materials definitely contain insightful information for task preparation. However, memorizing the formulaic expressions provided by these texts does not suffice to prepare students to succeed in real workplace contexts. Acquiring some specific strategies of linguistic and communicative nature will make students be more fluent in a job interaction. We assume that if students are made aware of the characteristics of real speech, which imply repetitions, backchannels and pauses, among others, then they could use some of these strategies to communicate more effectively, as Lin et al. (2012) indicated.

Within these theoretical perspectives, the treatment carried out tried to enhance the use of powerless speech styles in non-native speakers of English in terms of the new learning paradigm developed by the CEFR, with special regard to the workplace contexts of our students' future professional environments. 


\section{METHODOLOGY}

\subsection{Participants}

This treatment was carried out in a university computer engineering setting with 60 students of English, enrolled in a course devoted to develop fluency, accuracy, and quality in written and spoken language. The average age of the students was 21.6 and their level of English was B1, lower intermediate, at the beginning of the instruction phase, one of the levels of proficiency defined by the Framework ${ }^{1}$. The treatment undertaken was part of a course over a whole academic semester. Students met 3 hours weekly.

\subsection{Materials and procedure}

A preliminary phase, or pre-treatment study, consisted in the production of a negotiated agreement upon the benefits of using Linux versus Windows. This pre-treatment activity was run at the beginning of the course and measured pragmatic markers in oral and written interventions of the students in response to situational co-planning and groupwork. This activity was carried out in the computer lab by the participants through groupwork in a chatroom with a limitation of time of 15 minutes. The groups were formed by four students, two agreed on the benefits while the other two did not; a negotiated final decision was required online. A second step involved the delivery of this negotiation in front of the whole class with a limitation of 15 minutes as well. In this pre-treatment activity, no previous instruction on pragmatics had been provided to students. Oral interventions were recorded and the transcripts were coded based on the correct use of pragmatic style markers.

The second phase was the instruction phase, which aimed at helping students achieve an awareness of powerless markers by introducing the concept of powerful and powerless language in class. This theoretical input was followed by a detailed examination of text fragments, as proposed by Fragale (2006), and some exercises on this input. The exercises consisted mainly in comparing different scenarios of interactional exchanges, highlighting powerful and powerless devices and reflecting on their use by the working group. We also studied the communicative functions of these devices within particular contexts, since it is necessary for learners to identify these pragmatic factors before they can improve their competence, as indicated by Louw, Derwing and Abbott (2010). The lack of previous instruction on pragmatic competence required time to command the use of power markers, therefore, we dedicated one week to this phase, i.e., 3 hours.

A third phase, henceforth post-treatment study, aimed at using powerless markers appropriately in goal-oriented interactional exchanges, both in online written and spoken discourse, to develop pragmatic competence in L2. As in phase one, students first negotiated virtually upon the affordances of Open Source vs. Proprietary Software for 15 minutes 
maximum, then they acted out their roles in front of their classmates. The teacher acted as a mere listener and did not indicate any misunderstanding, as contended by Shiau and Adams (2011). These interactions were also recorded. Finally, the assessment and debriefing of the treatment highlighted its strong and weak outcomes.

\subsection{Data analysis}

In the pre-treatment study, the 60 subjects elaborated 15 online written co-planning interactions during 15 minutes, totalling around 20,000 words. From these interactions, following Biber (1988), we considered it more adequate to balance the corpus with the same number of words and randomly selected 1,000 words from each group's written exchanges. Likewise, the transcripts of the oral negotiations recorded a similar number of words; again a random selection of 1,000 words per group was examined. Accordingly, in the post-treatment study, which consisted of written and oral interactions delivered in front of the classroom for 15 minutes as well, the sample was balanced and a number of 1,000 words per group of each written and oral corpora were observed. Therefore, a tally of 60,000 words formed the data examined, whose results are detailed below.

As a valuable source of comparison, the outcomes of this study were compared with balanced chunks of written and spoken interactions produced by students with a similar profile who carried out the same subject the previous year; these participants did not receive instruction on powerful powerless language. These data, which constitute our Control Group, may give our study a wider scope.

\section{INTERPRETATION OF RESULTS}

The data obtained in the pre-treatment study performed at the beginning of the course, when no specific instruction had been provided to raise students' awareness of the pragmatics of power and language, is shown in Table 1 in the markers chosen as the most characteristic of powerless style (see Section 2).

The results of the pre-treatment study showed a global use of 580 powerless markers, an average of 29 markers in the 20 online written interactions, vs. 31 in oral interactions totalling 620 powerless markers, which meant a $6.4 \%$ lower rate in written contexts. In essence, the findings of this preliminary study later served to compare the use of the suitable powerless markers before and after instruction on pragmatic competence. As foreseen, these data were very similar to the result of written and spoken interactions in the Control Group ${ }^{2}$, a group of participants with no previous instruction on pragmatic markers as well.

Then, the instruction phase included the practical activities mentioned above to raise students' awareness of the difference between powerful and powerless style in 
communicative speech acts. The figures in Table 2 were obtained from the written and oral interactions developed, once the instruction phase had been completed.

\begin{tabular}{|l|c|c|}
\hline \multicolumn{3}{|c|}{ POWERLESS STYLE MARKERS: Pre-treatment data. } \\
Items per 1,000 words \\
\hline Categories & Written discourse & Oral discourse \\
\hline Hedges & 8 & 9 \\
\hline Tag questions & 0 & 0 \\
\hline Intensifiers & 8 & 7 \\
\hline Formal addresses and polite forms & 9 & 12 \\
\hline Hesitations & 0 & 0 \\
\hline Word repetitions & 0 & 0 \\
\hline Distancing techniques & 0 & 0 \\
\hline Disclaimers & 0 & 3 \\
\hline Parenthetical verbs & 4 & 0 \\
\hline Personalized epistemic modals & 0 & 31 \\
\hline TOTAL & 29 & 0 \\
\hline
\end{tabular}

Table 1. Powerless speech markers used before an instruction phase: written vs. spoken

\begin{tabular}{|l|c|c|}
\hline \multicolumn{3}{|c|}{$\begin{array}{c}\text { POWERLESS STYE MARKERS: Post-treatment data. } \\
\text { Items per 1,000 words }\end{array}$} \\
\hline Categories & Written discourse & Oral discourse \\
\hline Hedges & 14 & 10 \\
\hline Tag questions & 9 & 0 \\
\hline Intensifiers & 16 & 16 \\
\hline Formal addresses and polite forms & 15 & 14 \\
\hline Hesitations & 5 & 4 \\
\hline Word repetitions & 0 & 0 \\
\hline Distancing techniques & 0 & 0 \\
\hline Disclaimers & 4 & 5 \\
\hline Parenthetical verbs & 9 & 0 \\
\hline Personalized epistemic modals & 0 & 49 \\
\hline TOTAL & 72 & 0 \\
\hline
\end{tabular}

Table 2. Powerless speech markers found after an instruction phase 
It can be drawn from Tables 1 and 2 that pre-treatment and post-treatment data comparatively revealed a $59.7 \%$ increase in the use of powerless markers in written contexts, and $36.7 \%$ increase in oral contexts. In the post-treatment study, the students used a total of 1,440 powerless markers, 72 for every 1,000 words in the 20 online written interactions.

It is worth pointing out that the number of markers used in the first phase were similar to those obtained by Hyland (1998a) or Wishnoff (2000) in written contexts. In Wishnoff's study (2000), the students in the treatment group employed 15.55 hedges for every 1,000 words. Hyland (1998a) found that the average number of hedges in research articles was 20.6 per 1,000 words. On the other hand, the post-treatment results showed similarities to the data obtained by Parton, Siltanen, Hosman and Langenderfer (2002), who found 30 occurrences of powerless speech in interviewee messages of around 500 words. We need to clarify that, although their studies were restricted to what they had categorized as hedges, most of the markers they included are held under the category of powerless language adopted in our research. Consequently, their findings do not vary much from those found in our study, which showed a slightly higher use of these markers.

Additionally, it is interesting to underline that the data related to the written interactions outstandingly differed from the results of markers used in the oral negotiations delivered in class, which amounted to 980, 49 for every 1,000 words in the 15 oral interactions, much lower than those obtained in the online written negotiations ( $31.9 \%$ lower).

The detailed results on the types of power variables employed in the post-treatment study presented the following total numbers, framed in several categories. Only the most significant findings are commented upon together with some representative examples extracted from the written or the spoken interactions:

1. Hedges. The most frequently used hedging devices in our corpus were probably (51 occurrences in Writing, 12 in Speaking ${ }^{3}$ ), perhaps (42 in W., 20 in S.), more or less (41 in W., 22 in S.), etcetera (37 in W., 21 in S.), and so on (34 in W., 18 in S.). Among these, the use of and so on or etcetera is outstanding in situations where the interlocutor did not know of a possible continuation to the data or facts provided in his/her discourse, especially in face-to-face interactions. Example 1 shows how one participant in a conversation tried to keep on stating his point of view:

Example 1. The user is not allowed to share, redistribute the software or etcetera ....

It is interesting to observe that expressions of common use by native speakers of English were never found: e.g., as you know, an inclusive expression to involve the listener in inter-personal dialogues and conversation, and to convey a kind of mutual understanding of things; or the approximative expressions sort of or kind of. In fact, 
these expressions are prime examples of the type of meaningless 'fillers' that characterize the everyday speech of native speakers of English.

2. Tag questions were difficult to apply in this corpus, at least orally. Students found their use artificial, despite the fact that tag questions are often used in the students' mother tongue to involve the listener in a conversation.

3. Intensifiers were represented in our analysis by of course (50 occurrences in W., 32 in S.) and certainly (28 in W., 17 in S.) to signal evidence of the degree of confidence held by the speaker about the truth of the basic message as can be seen in Example 2:

Example 2. Certainly, the tendency observed nowadays is to use more and more open source software.

4. Formal addresses and polite forms were used naturally by the interlocutors, both in written texts and oral deliveries, as these politeness strategies behave similarly in the students' mother tongue. Thank you and please were the easiest to incorporate into the interactions.

5. Hesitation markers were not very frequently used in the written texts and scarcely in the spoken deliveries. In the recording of the dialogues, hesitations were manifested by holding back or pausing because of doubt. The following example of a dialogue uses a hesitation marker together with a pause in the statement:

Example 3. You must learn how to use open source yourself ..... well, if no manual is available.

6. Word repetitions did not occur in our corpus either by means of lexical repetition or by synonymy. The lexical cohesion pursued by the reiteration was substituted in our corpus for some reformulations of ideas mainly to make sure that the intended meaning of the message was properly understood by the interlocutors. Example 4 shows part of a written interaction where students reformulated their message:

Example 4. Open source software is developed at lower cost than proprietary software; open source software is interesting because of its price.

7. Distancing techniques were not representative in the corpus to diminish the commitment of interlocutors in conversation.

8. Disclaimers. As a result of the instruction phase, students forced their use in the online written interactions ( 8 occurrences per 1,000 words), but were not finally able to apply them in the face-to-face dialogues ( 0 occurrences in S.). 
9. Parenthetical verbs showed a strong preference for I think which rated the highest occurrence in both registers to manifest opinions (26 in W., 18 in S.). Other parenthetical verbs such as I believe, I assume, I guess, it would appear that, I suppose, I reckon, I feel that..., I mean, followed far behind. Example 5 shows how a parenthetical verb is used to introduce a discussion:

Example 5. I think that for big software platforms proprietary software seems to be better!

10. Personalized epistemic modals were not employed by the students, who showed a preference for using parenthetical verbs instead (such as I think or I believe).

\section{DISCUSSION AND CONCLUSIONS}

Results have revealed the difficulty involved in the development of pragmatic competence by non-native speakers of English. Our first hypothesis that, after specific instruction, students would be expected to show a better command of pragmatic competence in English, has been corroborated by the results. Nevertheless, this statement needs to be slightly nuanced since, although these non-native speakers of English succeeded in using pragmatic markers in written contexts, they still had difficulties in spoken discourse.

In the spoken corpus of this treatment, students' scarce use of these linguistic markers could be due to a possible influence of L1 behaviour, in other words, first language pragmatic transfer (Koike, 1996). In our case, the particular use of powerless speech style in the students' mother tongue may have prevented a fluent and appropriate use of this language variety, especially in oral performance. Indeed, as mentioned above in the theoretical framework of this study, Mediterranean cultures like Spanish tend to sound categorical and assertive when interacting, and avoid powerless style. Yet, the direct style used by these cultures does not correspondingly convey the impoliteness that native speakers of English may perceive in their straightforward interactions.

From a cross-cultural pragmatics perspective, the results of our study are in line with other investigations in the field. The problems entailed by the acquisition of pragmatic competence by Spanish students of English are similar to those found by Nikula (1997) and De Cock et al. (1998) with non-native speakers of a different mother tongue, since there is no doubt about the native character of powerless speech styles. Based on French speakers, De Cock et al. (1998) showed higher rates of powerless markers used by native speakers of English, as well as a richer variety. In the case of Nikula (1997), results sustained that nonnative speakers have the risk of sounding too formal or not natural if they use these linguistic markers. These markers are, undoubtedly, a native language resource; however, our treatment 
has shown that non-natives can overcome the problems in acquiring them, although the difficulty in using them fluently still persists. Despite these intricacies, favouring the language learners' sensitivity to these differences should aid in the development of pragmatic competence, as a similar study carried out by Wishnoff (2000) posited. Extensive practical activities may be useful in the internalization of the pragmatic mechanism and can, thus, contribute to enhance pragmatic competence. The task carried out was a first step to heighten students' pragmatic awareness.

Turning now to pragmatic competence in online written and spoken interactions comparatively, the second hypothesis, that powerless markers were likely to be used more adequately in writing than in oral interactions by students, has been fully confirmed. The potentially interesting reason for the asymmetry found could be based on the fact that written discourse is considered planned, whereas oral discourse is unplanned (Ochs, 1979). This implies that the online written interactions have been "thought out and organized (designed) prior to [its] their expression" (Ochs, 1979: 55). In general, written discourse allows time to adjust interactions to the conventions of the language and, consequently, a more fluent use of pragmatic strategies in writing. Conversely, oral discourse "lacks forethought and organizational preparation" (Ochs, 1979: 55). In our case, the oral interactions were in a middle position between both ends, that is, they did not involve oral production of impromptu language because they had been previously written, but, as they were hardly ever delivered literally, a certain amount of improvisation was involved in them, which is frequently the case in rehearsed oral L2 output (Menning, 2003). As a result of improvisation, the participants in our treatment could not systematically employ adequate powerless markers in their spoken rehearsed delivery as they improvised in their interactions, which is in sharp contrast to the studies by Mennim (2003) or Yuan and Ellis (2003) where students were able to incorporate the feedback of the teacher while speaking naturally occurring speech. In most cases, our participants' interactions, in spite of being previously planned, did not follow the patterns of planned discourse due to the pressure of being recorded and assessed. To conclude in this regard, it is important to bear in mind that online written discourse in chatrooms does not totally adjust to the standards of traditional written discourse and cannot be considered as purely planned discourse because it is synchronously produced and writers may have less time to elaborate these written interactions than in traditional writing.

All in all, owing to the mixed nature of these oral interactions, the introduction of these pragmatic devices in conversation was not as straightforward as in the online planned written interactions. The results drawn from the application of powerless markers in the oral and written examples may lend weight to the hypothesis that native pragmatic competence is deeply rooted. Therefore, it may require gradual internalization through further practice before it comes up more naturally. Pragmatic competence in L2 would need, then, more time to be used fluently, especially in face-to-face conversations. 
Finally, it is necessary to point out that these results must be considered within a set of limitations since the sample size of this treatment was small and was limited to college students. Our results might be different in real situations where status and power differences are greater; there will be significant distinctions in speech patterns as well, as Grob et al. (1997) suggested in their study about how sex differences affect the preference of powerful/powerless language.

\section{IMPLICATION OF THE STUDY AND FURTHER RESEARCH}

From an educational perspective, the study has shed light on the complexity of pragmatic competence to be successfully acquired by non-native learners of English, owing to the difficulty encountered in perceiving, learning, and correctly using powerless and powerful styles. However difficult it may seem, enhancing pragmatic competence is important, especially in higher levels of proficiency, since lack of pragmatic competence "can create serious problems for a second language speaker" (Fraser, 2010: 15).

The findings have obvious implications for language teaching. The inclusion of powerful and powerless speech in the English language syllabi, as suggested by many scholars such as Johnson (1987), has complied with the requirements of the CEFR. Besides, a discursive approach to teaching and learning language strategies may be useful and benefit tertiary students who are preparing themselves to interact in workplaces, as Lin et al. (2012) recommend. The application of the treatment here addressed has enhanced the development of a variety of skills, not only linguistic but also personal and job skills, a challenge aimed at professional competitiveness and employability (Montero-Fleta, 2012). Further innovations can be introduced for the practice of language styles in the English classroom and in other communicative situations as well, like public speaking, persuasion or interpersonal communication. The need to overcome the difficulties encountered by non-native students in the adequate use of pragmatic competence requires more practical studies and new pedagogical materials to help students internalize pragmatic conventions.

Our study could give rise to other issues such as the influence of unplanned discourse in pragmatic competence, a future line of research which could compare online written discourse to traditional written discourse in workplace contexts. Further studies could also deal with hands-on activities to use these markers in authentic contexts. Gender distinctions in the use of language varieties in specialized learning contexts could be addressed, in the line of thought of recent studies which have compared the use of powerless language by men and women. 


\section{NOTES}

1. These levels, which range from $\mathrm{A} 1$ to $\mathrm{C} 2$, permit measuring learners' progress at each stage of learning on a life-long basis for several European languages.

2. Due to the similarity of the results of the Control Group and pre-treatment data, only the latter are shown in detail in this section.

3. Writing and Speaking will be referred to as W. and S. throughout the Results section.

\section{REFERENCES}

Biber, D. (1988). Variation across speech and writing. Cambridge: Cambridge University Press.

Blankenship, K. L. \& Holtgraves, T. (2005). The role of different markers of linguistic powerlessness in persuasion. Journal of Language \& Social Psychology, 24(1), 3-24.

Blum-Kulka, S. (1997). Discourse pragmatics. In T. A. Van Dijk (Ed.), Discourse and social interaction (pp. 38-63). Thousand Oaks, Ca.: Sage.

Bradac, J. J. \& Mulac, A. (1984). A molecular view of powerful and powerless speech styles: Attributional consequences of specific language features and communicator intentions. Communication Monographs, 51, 307-319.

Chafe, W. (1982). Integration and involvement in speaking, writing, and oral literature. In D. Tannen (Ed.), Spoken and written language. Exploring orality and literacy (pp. 35-53). Norwood, NJ: Ablex.

Coates, J. (1988). Gossip revisited: Language in all-female groups. In J. Coates \& D. Cameron (Eds.), Women in their speech communities (94-122). London: Longman.

Council of Europe (2001). Common European Framework of Reference for Languages. Retrieved from $\mathrm{http} / / / \mathrm{www}$. coe.int/t/dg4/linguistic/cadre_en.asp

De Cock, S., Granger, S., Leech, G. \& McEnery, T. (1998). An automated approach to the phrasicon of EFL learners. In S. Granger (Ed.), Learner English on Computer (pp. 67-79). London: Longman.

Duff, P. A. (2005). Thinking globally about new literacies: Multilingual socialization at work. In J. Anderson, M. Kendrick, T. Rodgers, \& S. Smythe (Eds.), Portraits of literacy across families, communities, and schools (pp. 341-362). Mahwah, NJ: Erlbaum.

Durik, A. M., Britt, M. A., Reynolds, R. \& Storey, J. (2008). The effects of hedges in persuasive arguments: A nuanced analysis of language. Journal of Language and Social Psychology, 20(10), 1-18.

Fragale, A. R. (2006). The power of powerless speech: The effects of speech style and task interdependence on status conferral. Organizational Behavior and Human Decision Processes, $101,243-261$.

Fraser, B. (1980). Conversational mitigation. Journal of Pragmatics, 4, 341-350.

Fraser, B. (2010). Pragmatic competence: The case of hedging. In G. Kaltenbock, W. Mihatsch \& S. Schneider (Eds.), New Approaches to Hedging (pp.15-35). UK: Emerald Group Publishing Limited.

Gómez González, M. A. (2012). A reappraisal of lexical cohesion in conversational discourse. Applied Linguistics, 34(2), 128-150.

Grob, M. L., Meyers, R. A. \& Shuh, R. (1997). Powerful/powerless language used in group interactions: Sex differences or similarities. Communication Quarterly, 45(3), 282-303.

Halvorsen, K. (2013). Team decision making in the workplace: A systematic review of discourse analytic studies. Journal of Applied Linguistics and Professional Practice, 7(3), 273-296.

Hyland, K. (1998a). Hedges in scientific research articles. Amsterdam: John Benjamins.

Hyland, K. (1998b). Boosting, hedging and the negotiation of academic knowledge. Text, 18(3), 349382.

Johnson, C. E. (1987). An introduction to powerful and powerless talk in the classroom. Communication Education, 26(2), 67-72. 
Kasper, G. \& S. Blum-Kulka, S. (Eds.). (1993). Interlanguage pragmatics. New York: Oxford University.

Koike, D. A. (1996). Transfer of pragmatic competence and suggestions Spanish foreign language learning. In Gass, S. \& Neu, J. (Eds.), Speech Acts Across Cultures. Challenges to Communication in a Second Language (pp. 257-281). Berlin: Mouton de Gruyter.

Koike, D. A. \& Pearson, L. (2005). The effect of instruction and feedback in the development of pragmatic competence. System, 33(3), 481-501.

Lakoff, G. (1972). Hedges: A study of meaning criteria and the logic of fuzzy concepts. In Peranteau P., J. Levi \& G. Phares (Eds.), Papers from the Eight Regional Meeting of Chicago Linguistic Society (pp. 183-228). Chicago: Chicago University Press.

Leech, G. (1993). Principles of Pragmatics. London: Longman.

Lin, T, Tan, R., Taib, F. \& Ling, C. (2012). A discursive approach to interactions at job interviews and its implication for training. English for Specific Purposes World, 36(12), 1-14.

Lipokvsky, C. (2010). Negotiating solidarity: A social-linguistic approach to job interviews. Newcastle upon Tyne: Cambridge Scholars Publishing.

Louw, K. J., Derwing T. M., \& Abbott, M., (2010). Teaching pragmatics to L2 learners for the workplace: The job interview. The Canadian Modern Language Review/La Revue Canadienne des Langues Vivantes, 66(5), 739-758.

Markkanen, R., \& Schröder, H. (Eds.) (1997). Hedging and discourse: Approaches to the analysis of a pragmatic phenomenon in academic texts. Berlin: de Gruyter.

Marra, M., Holmes, J. \& Riddiford, N. (2009). New Zealand's language in the workplace project: Workplace communication for skilled migrants. Language in the Workplace Occasional Papers, 1, 1-20.

Mennim, P. (2003). Rehearsed oral L2 output and reactive focus on form. ELT Journal, 57(2), 130138.

Michael, A. S., M., Chrone, L. S., Muthusamy, C., \& Veeravagu, J. (2010). Gendered-linked differences in speech styles: Analysing linguistic and gender in the Malaysian context. CrossCultural Communication, 6(1), 18-28

Montero-Fleta, B. (2012). Looking beyond linguistic outcomes: Active learning and professional competencies in higher education. Procedia-Social and Behavioral Sciences, 46, 1812-1819.

Newton, J. \& Kusmierrczyk, E. (2011). Teaching second languages for the workplace. Annual Review of Applied Linguistics, 31, 74-92.

Ng, S. H. \& Bradac, J. J. (1993). Power in language. Verbal communication and social influence. NewburyPark: Sage.

Nikula, T. (1997). Interlanguage view on hedging. In R. Markkanen \& H. Schröder (Eds.), Hedging and Discourse: Approaches to the Analysis of a Pragmatic Phenomenon in Academic Texts (pp. 188-207). Berlin: Walter de Gruyter.

North, B. (2004). Europe's framework promotes language discussion, not directives. Guardian Weekly, 15 April. Retrieved from: http://www.guardian.co.uk/education/2004/apr/15/tefl6

O'Barr, W. M. (1982). Linguistic evidence: Language, power, and strategy in the courtroom. New York: Academic Press.

Ochs, E. (1979). Planned and unplanned discourse. Syntax and semantics, 12, 51-81.

Pérez-Sabater, C. (2012). A pioneer study on online learning environments following the Common European Framework of Reference for Languages. Procedia-Social and Behavioral Sciences, 46, 1948-1955.

Pletger, P. (2007). English for Human Resources. Oxford Business English. Oxford. Oxford University Press

Parton, S. R., Siltanen, S. A., Hosman, L. A., \& Langenderfer, J. (2002). Employment interview outcomes and speech style effects. Journal of Language and Social Psychology, 21(2), 144161.

Riddiford, N. (2007). Making requests appropriately in a second language: Does instruction help to develop pragmatic proficiency? TESOLANZ Journal, 15, 88-103.

Riddiford, N. \& Joe, A. (2010). Tracking the development of sociopragmatic skills. TESOL Quarterly, 44(1), 195-205. 
Shiau, Y.S.S. \& Adams, R. (2011). The effects of increasing reasoning demands on accuracy and complexity in L2 oral production. Papers in TESOL, 6, 121-146.

Tannen, D. (1987). Repetition in conversation as spontaneous formulaicity. Text, 7(3), 215-243.

Tanskanen, S.K. (2006). Collaborating towards coherence: Lexical cohesion in English discourse. Amsterdam: John Benjamins Publishing Company.

Taweel, A. Q., Saidat, E. M. R., Hussein, A. \& Saidat, A. M. (2011). Hedging in political discourse. The Linguistic Journal, 5(1), 169-196.

Wishnoff, J. R. (2000). Hedging your bets: L2 learners' acquisition of pragmatic devices in academic writing and computer-mediated discourse. Second Language Studies, 19(1), 119-148.

Yates, L. \& Springall, J. (2010). Soften up! Successful results in the workplace. In D. Tatsuki, \& N. Houck (Eds.), Pragmatics from Research to Practice: Teaching Speech Acts (pp. 67-86). Alexandria, VA: Tesol.

Yeung, L. (2007). In search of commonalities: Some linguistic and rhetorical features of business reports as a genre. English for Specific Purposes, 26, 156-179.

Yuan, F. \& Ellis, R. (2003). The effects of pre-task planning and on-line planning on fluency, complexity and accuracy in L2 monologic oral production. Applied Linguistics, 24(1), 1-27. 